\title{
Changes in milk yield, lactate dehydrogenase, milking frequency, and interquarter yield ratio persist for up to 8 weeks after antibiotic treatment of mastitis
}

\author{
K. K. Fogsgaard, ${ }^{* 1}$ P. Løvendahl,† T. W. Bennedsgaard, ${ }^{*}$ and S. Østergaard* \\ *Department of Animal Science, and \\ †Department of Molecular Biology and Genetics, Aarhus University, AU-Foulum, 8830 Tjele, Denmark
}

\begin{abstract}
Within the dairy industry, the appearance of milk and withdrawal time due to antibiotic residuals in the milk are used to determine recovery status after cases of treated mastitis. However, both milk production and dairy cow behavior have been shown to be affected after the normalization of milk appearance, indicating that animals may not have fully recovered. The aim of the present study was to describe the changes in milk yield, lactate dehydrogenase activity, milking frequency, and interquarter yield ratio (defined as the coefficient of variation between the active quarters) after cases of naturally occurring mastitis with special focus on the recovery period after antibiotic treatment. A second aim was to examine whether these changes were affected by the pathogens present at the time of mastitis diagnosis. This retrospective study was based on a cohort data set including 1,032 lactations from 795 dairy cows kept on 2 Danish farms and milked by an automatic milking system. A total of 174 treated mastitis cases were compared with nontreated control cows from 5 wk before treatment and until 8 wk after. Treated mastitis resulted in reduced milk yield, elevated lactate dehydrogenase activity, lower milking frequency, and elevated interquarter yield ratio. Within these measures, deviations from baseline levels and from the control cows were found as early as 1 to $3 \mathrm{wk}$ before the antibiotic treatment and peaked around the days of treatment. In some cases, the mastitic cows returned to premastitis levels, whereas in others they remained affected throughout the rest of the observation period. To correctly estimate the effects of treated mastitis and the recovery status of cows, it is important to take the individual cow into account and not only compare
\end{abstract}

Received December 7, 2014.

Accepted July 31, 2015.

${ }^{1}$ Corresponding author: Katrine.KopFogsgaard@anis.au.dk with herd levels, as this might mask the true degree of the changes. The effects on each outcome variable depended on the involved pathogen and differences were found between primiparous cows and older animals. However, in general, the changes in milk production, lactate dehydrogenase activity, and interquarter yield ratio showed parallels, suggesting that the recovery period continued for weeks after antibiotic treatment. These results call for further investigation into management of mastitic dairy cows to optimize recovery, limit milk loss, and ensure animal welfare during the period after mastitis.

Key words: dairy cow, mastitis, recovery, automatic milking system, lactate dehydrogenase

\section{INTRODUCTION}

For decades, research has focused on early identification of dairy cows with mastitis. Several diagnostic tools have been developed and can be combined in mastitis-control programs (Rutten et al., 2013). The recovery period following mastitis has received less scientific attention. Within the dairy industry, the appearance of the milk and lack of antibiotic residuals in the milk are used to determine recovery after cases of naturally occurring mastitis. However, previous studies have shown that cows have elevated SCC and decreased milk production at least $8 \mathrm{wk}$ after mastitis (Gröhn et al., 2004; Schukken et al., 2009a; Hertl et al., 2014). Hence, data already available on-farm in the modern dairy industry may reveal new insights into recovery after mastitis; however, at present, this phase is not well understood.

Analyses of SCC in composite milk samples (milk mixed from all active quarters) are most commonly used as an indicator of mastitis (Nyman et al., 2014), but other udder health indicators also exist, such as inline measurements of lactate dehydrogenase $(\mathbf{L D H})$. The LDH enzyme is part of the glycolytic pathway, present in the cytoplasm of all cells. During udder infection, the activity of LDH in composite milk increases as a result 
of disrupted udder tissue (Bogin et al., 1976). This increase has been shown to be a responsive indicator of mastitis and is currently being used for early detection of bovine mastitis (Chagunda et al., 2006b; Nyman et al., 2014).

Most cases of mastitis occur at quarter level, whereas most of the present diagnostic tools focus on cow level. Use of the interquarter ratio (IQR) of milk yield may be one way to estimate the level of mastitis at quarter level. The IQR is the coefficient of variation between the active quarters. This is supported by the finding that the IQR of electric conductivity can successfully distinguish between healthy and clinically infected cows (Norberg et al., 2004). Hence, the IQR of yield might serve as a valid measure of the ability of the udder to reach a stable level of milk production after a mastitis incident. If so, large IQR variation and fluctuations in the IQR variation may indicate lack of recovery after mastitis.

Cows milked by automatic milking systems (AMS) have some possibility to change their milking frequency, which would be expected during times of disease as a result of discomfort and malaise. During mastitis, being milked might be an aversive experience due to soreness of the udder (Fitzpatrick et al., 1998; Leslie et al., 2010), thus should be delayed or even avoided, if possible. Hence, in housing systems using AMS, the magnitude and duration of changes in milking frequency might contain information about the mastitis status of individual cows.

Here we report results from a retrospective study of 174 cases of treated mastitis from 2 Danish herds using AMS to achieve insights into the recovery phase after naturally occurring mastitis treated with antibiotics. We aimed to describe the changes in milk yield, LDH activity, milking frequency, and IQR of yield in primiparous and multiparous cows. A second aim was to examine whether these changes were affected by the mastitis-causing pathogens present at the time of diagnosis: Staphylococcus aureus, CNS, and Escherichia coli.

We hypothesized that several of the milk productionrelated traits connected to the function of the udder would be affected by mastitis - particularly the traits connected to the infected quarter(s). After antibiotic treatment, the response to mastitis was expected to differ in these 2 groups of cows and also for the types of pathogens involved. Based on previous research (Gröhn et al., 2004; Schukken et al., 2009a; Hertl et al., 2014) and the differences in the lactation curves of primiparous and multiparous cows (Wood, 1969), the response to treated mastitis in these 2 groups of cows was expected to differ and similarly for the types of pathogens involved.

\section{MATERIALS AND METHODS}

\section{Design, Herds, and Animals}

This study was designed as a retrospective cohort study (Ersbøll et al., 2004) with multivariate, irregularly spaced time series data. The initial data set included records from dairy cows $<305$ DIM and parity 1 to 3 , recorded on 2 farms (Jutland, Denmark) from January 2010 (farm A) and November 2012 (farm B) to July 2014. Cows in parity 4 and later were excluded. Both farms were freestall dairy herds with AMS. Farm A milked an average of 210 dairy cows, both Jersey and Holstein-Friesian, in 3 milking units (on average $2.9 \pm$ 0.8 milkings/cow per day) and fed a balanced TMR in automatic feeding bins (Ric Systems, Insentec, Marknesse, the Netherlands). Farm B milked an average of 260 Holstein-Friesians in 4 milking units (on average $2.8 \pm 0.8$ milkings/cow per day), and cows were fed a balanced TMR via feed alleys. On both farms, cows were supplied with concentrates in restricted amounts while being milked. The feed ration provided during any milking was controlled by the settings of the AMS software and based on time since last milking. On both farms, AMS had free cow traffic with the following settings of the robot: cows $\leq 150$ DIM could only be milked with a minimum interval of $5 \mathrm{~h}$ or $7 \mathrm{~kg}$ of milk per milking, whereas cows $>150$ DIM were allowed to be milked with an interval of minimum $8 \mathrm{~h}$ or $8 \mathrm{~kg}$ of milk per milking. The AMS software (DeLaval, Tumba, Sweden) calculated the milking interval of individual cows based on information from previous milkings and DIM. Irrespective of the DIM, cows with a milking interval exceeding $15 \mathrm{~h}$ were fetched for milking by barn staff twice a day.

\section{Outcome Variables}

The 4 response variables of interest were milk yield, LDH activity, milking frequency, and the IQR of yield. Daily milk production at udder and quarter level (for quarter level only on farm A) was recorded automatically by the AMS. The $24-\mathrm{h}$ milk yield $(\mathrm{kg} / \mathrm{d})$ was calculated as a 3-d moving average yield per $24 \mathrm{~h}$, as suggested by ICAR (2011), taking yield per milking and milking frequency into account. This was done to reduce the effect of randomly occurring values for a particular milking. For the daily milking frequency, the mean number of milkings for the last $3 \mathrm{~d}$ was used to take the last $72 \mathrm{~h}$ into account. All milkings, including those where the cows had been fetched for milking, were included in the data.

On both farms, milk samples for LDH activity ( $\mu \mathrm{mol} / \mathrm{min}$ per liter) were taken automatically during 
each milking in the AMS by the Herd Navigator system (DeLaval). Briefly, based on previous and current $\mathrm{LDH}$ levels combined with cow factors, an integrated model calculated the risk of mastitis and the following sampling frequency (further details in Chagunda et al., 2006a). No smoothing of LDH measurements was done, as these were not measured as frequently as milk yield. For cows from farm A, the IQR of yield was calculated as the coefficient of variation for nonsmoothed quarter yield at each milking. The coefficient of variation represents the ratio of standard deviation to the mean, showing the variation in the contribution of each quarter to the total milk yield.

\section{Detection of Mastitis}

Cows with potential mastitis were identified automatically at milking by increased levels of SCC or LDH. The online cell counter (DeLaval) and the Herd Navigator system evaluated the risk of mastitis based on the development in SCC and $\mathrm{LDH}$, respectively. In individuals where levels of LDH increased above an individually calculated threshold, the system alerted the farm personnel about the increased risk of mastitis for that specific cow (see further details in Chagunda et al., 2006a). To confirm the presence of mastitisclinical or subclinical - farm personnel collected aseptic milk samples from the identified cows for bacteriological culturing. The bacteriological culture procedures were performed according to the National Mastitis Council's Laboratory Handbook on Bovine Mastitis (National Mastitis Council, 1999). Samples with 2 or more colonies were considered positive $(\geq 200 \mathrm{cfu} / \mathrm{mL})$. When 3 or more pathogens were recorded in the same milk sample, the sample was considered contaminated $(\mathrm{n}=1)$. Type and dose of antibiotic treatment were determined by the treatment protocol administrated at the time in question. Local and systemic antibiotic treatment was administered at d 0 , whereas treatments on $\mathrm{d} 1$ and 2 were systemic. The applied active pharmaceutical drugs were procaine benzyl penicillin, amoxicillin, cloxacillin, or ampicillin.

\section{Case Definition}

In the present data set, treated mastitic (TM) cows included cows with one antibiotic treatment for mastitis during a lactation. Cows with more than one treatment during the same lactation were excluded from the data, as the recovery phase could not be identified. Cows without records of antibiotic mastitis treatment during one lactation were included as nonmastitic control cows. Within individual cows, single lactations were considered independent, and cows could thus be included in the data set in several lactations and serve as either a control or a mastitis case independently of their status during other lactations. Based on the culturing of the milk samples, 3 main categories of mastitis-causing pathogens were identified: Staphylococcus aureus, CNS, and Escherichia coli. In addition, a fourth category was created (other pathogens) including all cases of TM caused by all types of pathogens and cases without bacterial growth or where results from the bacterial culture were lacking. When modeling each of the 3 main categories of pathogens, the other 2 main categories of pathogens were included in category 4 .

\section{Statistical Analysis}

The fixed effects of one case of antibiotic-treated mastitis, parity, week-in-milk (WIM), calving season, and herd on 4 variables (milk yield, LDH, milking frequency, and IQR of yield) were examined using mixed models (PROC MIXED in SAS Enterprise Guide software Version 5.1, SAS Institute Inc., Cary, NC). The random effects were modeled with individual cow within lactation as subjects, taking into account that measurements on the same cow within each lactation were correlated. For the residual variance, 4 correlation structures (compound symmetry, unstructured, spatial power, and first-order autoregressive) were compared using likelihood ratio tests. These results showed that either spatial power or first-order autoregressive symmetry were preferred. Based on goodness-of-fit measures, including Akaike's information criterion (lowest values preferred) and the Bayesian information criterion, the first-order autoregressive correlation structure was chosen for all the final models. In the first-order autoregressive model, the correlations depend on the time between the observations and the correlations decrease exponentially with time. It is also biologically reasonable to assume that the 4 kinds of measurements included in the present study will follow this correlation structure, as measurements at the same stage of lactation are more strongly correlated than measures taken further apart in time. Post hoc analyses of factor level comparisons for the effects of week were calculated using a pairwise method and the Bonferroni correction for multiple comparisons. The development over time in relation to TM was modeled using a mastitis index (MI) with 15 levels. Here, one level represented all control cows in that lactation, and 14 levels represented the week of measurement in relation to antibiotic treatment. The 14 levels were denoted as wk -5 to 8 . All levels were equivalent to $1 \mathrm{wk}$, except levels -5 and 8 , which included $14 \mathrm{~d}$ to achieve a more solid start and end point. This was taken into account in the numbering of the different levels when the variable was included in 
the mixed models, to ensure it was modeled correctly when choosing the correlation pattern. Calving season was split into 4 categories: March through May, June through August, September through November, and December through February. Herd had 2 levels (A and B). Parity was divided into 2 groups $(1$ and $\geq 2)$, where primiparous and multiparous cows (second and third lactation) were modeled separately for all 4 response variables. Week-in-milk had 43 levels and was included as a categorical variable to take lactation stage into account.

In multiparous cows, the effect of TM on the 4 response variables $(\mathrm{Y})$ was modeled by

$$
\begin{aligned}
\mathrm{Y} & =\mathrm{MI}_{m}+\text { calving season }_{s}+\mathrm{WIM}_{w} \\
& +\operatorname{herd}_{h}+\text { parity }_{p}+\operatorname{cow}_{c h p}+e
\end{aligned}
$$

where $\operatorname{cow}_{c h p}$ was the random effect of the individual cow nested within herd and parity and $e$ was an error term representing within-cow variance of each response variable. A similar model, but without parity, was used for primiparous cows.

Comparison of TM caused by each category of pathogens versus all other pathogens was done by an extension of the above mentioned model. For each of the pathogen categories, a binary variable $(0 / 1)$ was created and included as an interaction with the mastitis index (shown here for $S$. aureus) for primiparous and multiparous cows, respectively:

$$
\begin{aligned}
& \mathrm{Y}=\mathrm{MI}_{m} \times \text { S. } \text { aureus }_{a}+\text { calving season } \\
& \\
& +\mathrm{WIM}_{w}+\operatorname{herd}_{h}+\text { parity }_{p}+\text { cow }_{h c p}+e .
\end{aligned}
$$

Throughout, the degrees of freedom were calculated using Satterthwaite's approximation. Results are given as adjusted least squares means \pm standard error, unless otherwise noted. Results were considered significant when $P$-values were $<0.05$ and as a tendency when 0.05 $\leq P<0.1$.

\section{Loss of Milk Production}

Loss of milk production due to TM compared with control cows was calculated as the area between the 2 curves in the MI weeks. The milk loss of TM cows, compared with the expected milk yield in the case of no TM in the same cows, was estimated. Least squares means from the above described mixed models for wk -5 were set as the expected yield during the entire observation period if the TM case had not occurred. The milk loss due to TM was estimated as the differences between the expected curve and the observed curve during the entire observation period. For all analyses of milk loss, the estimated least squares means from the previously mentioned models were used, taking WIM into account.

\section{RESULTS}

\section{Descriptive Findings}

The present results are based on a total of 518 primiparous lactations and 514 multiparous lactations for up to 305 DIM. Table 1 shows the distribution of individuals according to herd, disease status, and pathogens for primiparous and multiparous cows. Mastitis cases involving antibiotic treatment occurred more frequently in multiparous than in primiparous cows. Treated mastitis caused by CNS occurred most frequently in primiparous cows, whereas $S$. aureus was the most common pathogen in the multiparous cows.

\section{Effects of Treated Mastitis}

The highest estimated milk loss was seen in primiparous cows when compared with control cow production, whereas estimated milk losses, when compared with premastitis levels within the TM cases, were highest in the multiparous cows (Table 2). The development of the 4 variables in relation to day of treatment is shown in Figure 1 as estimated least squares means for primiparous and multiparous cows. Milk yield of primiparous TM cows resembled that of the controls until 1 wk before treatment, when the yield declined and remained lowered throughout the observation period. In the multiparous cows, the milk yield before TM was higher than in controls, but declined to a nadir in the week of treatment. Lactate dehydrogenase levels were similar in TM and control cows for both primiand multiparous cows until 3 wk before treatment and then peaked in wk 0 . Lactate dehydrogenase returned to baseline levels at wk 7 for primiparous cows $(P>$ $0.05)$, but even though a plateau was reached for the multiparous cows, the LDH activity of these animals remained elevated throughout the study period $(P<$ $0.001)$.

In multiparous cows, the milking frequency was lowered from wk -4 onward compared with control cows $(P<0.01)$; hence, it was lower at baseline than at the finalization of the study period (wk -5 vs. $8 ; P$ $<0.001)$. This development was not seen in the primiparous cows, where the milking frequency remained unaffected by TM. The observed changes in IQR of yield before treatment for TM resembled the findings for total milk yield, although with a later response in the multiparous TM cows. Across parities, the IQR of 
Table 1. Demographic information regarding number of treated mastitis cases, pathogens, milk yield, lactate dehydrogenase (LDH) activity, milking frequency, and interquarter yield ratio (all data are mean $\pm \mathrm{SD}$ ) at herd and parity level for 1,032 lactations included in this retrospective study of recovery after treated bovine mastitis ${ }^{1}$

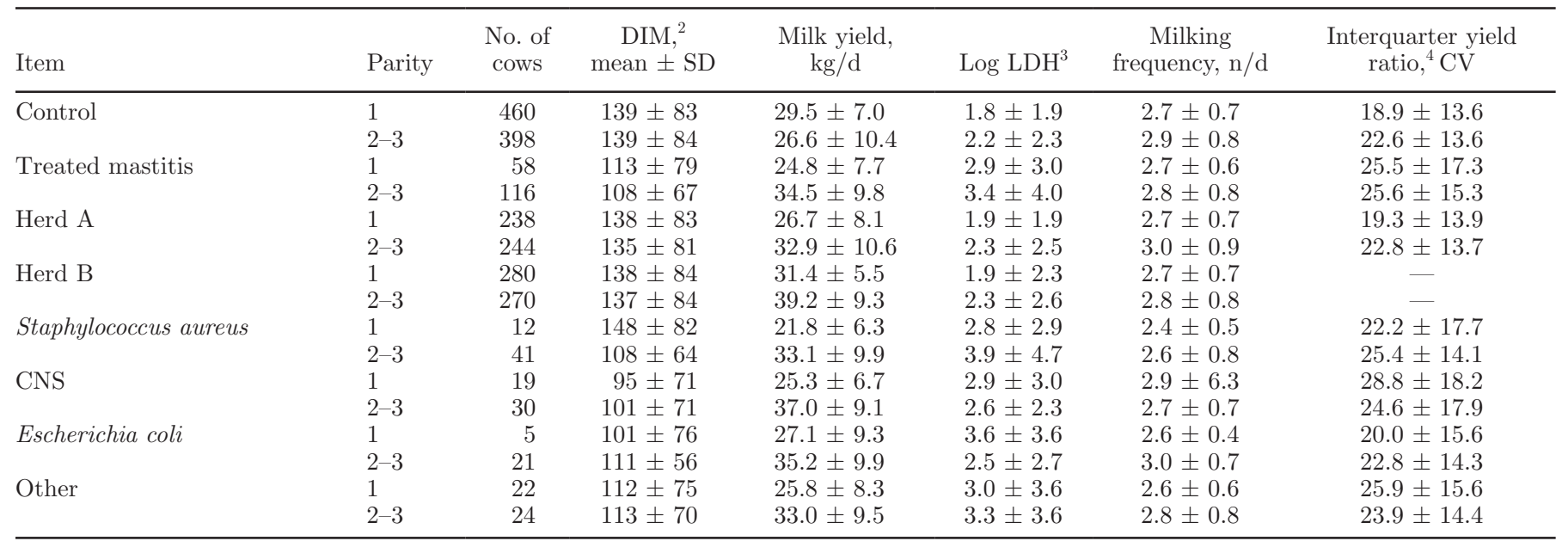

${ }^{1}$ The information is stratified by the 3 most abundant pathogen groups in the present data (E. coli, S. aureus, and CNS).

${ }^{2}$ Calculated from the means of DIM for all individual cows included in each of the groups. For example, for parity $1 S$. aureus cows, $148 \pm 82$ is the overall mean DIM for that group and is calculated based on the mean DIM values for the 12 individual cows included in the $S$. aureus group. ${ }^{3}$ Logarithmic values of LDH activity.

${ }^{4}$ Calculated as the CV for quarter yield with only data from farm A.

yield was higher at the end of the study period (wk 8) compared with baseline levels (wk $-5, P<0.001$ ).

\section{Effects of Specific Pathogens}

Staphylococcus aureus. Overall, the development over time for the 4 variables in $S$. aureus-infected cows resembled the development in other types of mastitis, but showed larger responses for the primiparous cows. Figure 2 shows changes in the 4 variables (plotted as the least squares means from model 2) in relation to day after antibiotic treatment. Primiparous cows infected with $S$. aureus had a lower milk yield and milking frequency than primiparous controls and primiparous cows infected with the other pathogens. Except for wk 0 , the milk yield of cows in parity $\geq 2$ infected with $S$. aureus did not deviate from that of the control cows $(P>0.05)$. The estimated milk losses were between 92 and $531 \mathrm{~kg}$ depending on parity, the mastitis-causing pathogen, and whether the milk yield was compared with individual premastitis levels or the control group. Further details can be seen in Table 2. For multiparous cows with $S$. aureus, the LDH activity was increased compared with the other pathogen categories, whereas the IQR of yield did not differ between the 2 infection groups $(P>0.05)$. In primiparous cows, no differences were observed in LDH activity between $S$. aureus mastitis and mastitis caused by the other pathogens. The development in IQR of yield deviated from the other pathogens.
$\boldsymbol{C N S}$. The development in milk yield, LDH, milking frequency, and IQR of yield in cows with CNS mastitis is shown in Figure 3 as least squares means from model 2. The CNS-infected multiparous cows had an overall higher milk yield and lower LDH levels premastitis, and the primiparous cows showed an overall higher IQR of

Table 2. Milk yield of the 174 lactations from cows diagnosed and treated for mastitis once during the present lactation as well as the 858 control lactations ${ }^{1}$

\begin{tabular}{lcc}
\hline & \multicolumn{2}{c}{$\begin{array}{c}\text { Treated mastitis cases } \\
\text { compared with }\end{array}$} \\
\cline { 2 - 3 } & $\begin{array}{c}\text { Control cows, } \\
\mathrm{kg}(\%)\end{array}$ & $\begin{array}{c}\text { Mastitis cow } \\
\mathrm{wk}-5)^{3} \\
\mathrm{~kg}(\%)\end{array}$ \\
\hline Item & $-228.0(7.4)$ & $-214.1(6.9)$ \\
\hline All pathogens & $-111.0(4.7)$ & $-315.1(7.7)$ \\
$\quad$ Parity 1 & $-504.3(16.3)$ & $-142.5(5.2)$ \\
Parity 2-3 & $-173.0(6.6)$ & $-376.7(9.4)$ \\
Staphylococcus aureus & $-216.6(9.1)$ & $-531.1(12.5)$ \\
Parity 1 & $-182.4(7.2)$ & $-279.7(8.7)$ \\
Escherichia coli & & $-92.5(2.3)$ \\
Parity 2-3 & $211.1(5.6)$ & \\
CNS & Parity 1 & \\
Parity 2-3 &
\end{tabular}

${ }^{1}$ The observation period covered wk -5 to 8 after antibiotic treatment. ${ }^{2}$ Summed over weeks where mastitic cow yield $<$ control cow yield.

${ }^{3}$ Actual milk yield compared with milk yield from wk -5 extrapolated to all $14 \mathrm{wk}$. Summed over entire observation period.

${ }^{4}$ Too few E. coli cases in parity 1 to be included as a separate group. 


\section{Primiparous cows}

Milk yield

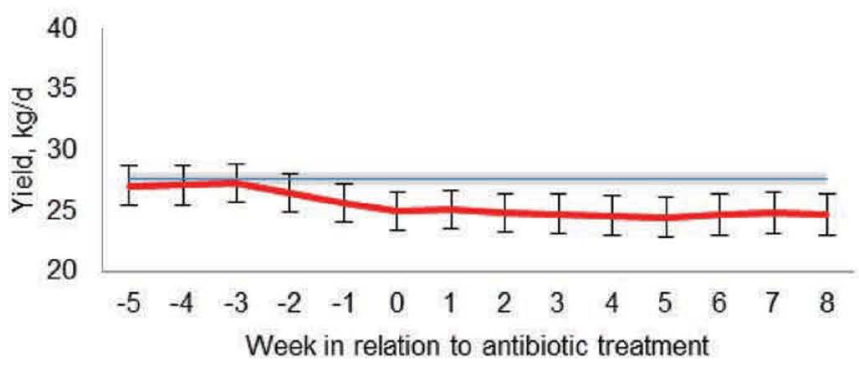

Lactate dehydrogenase

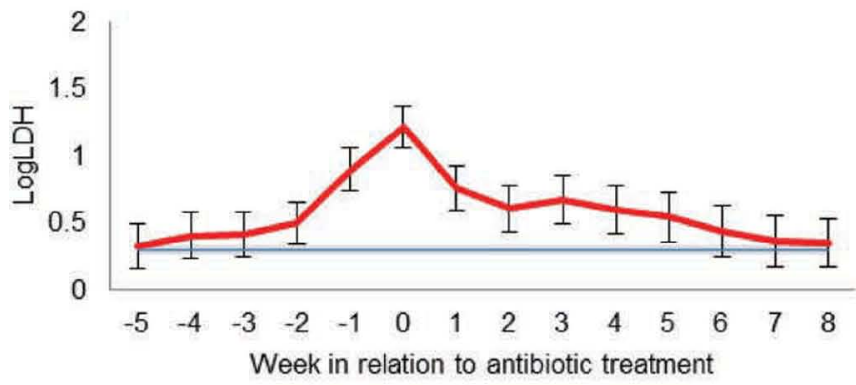

Milking frequency

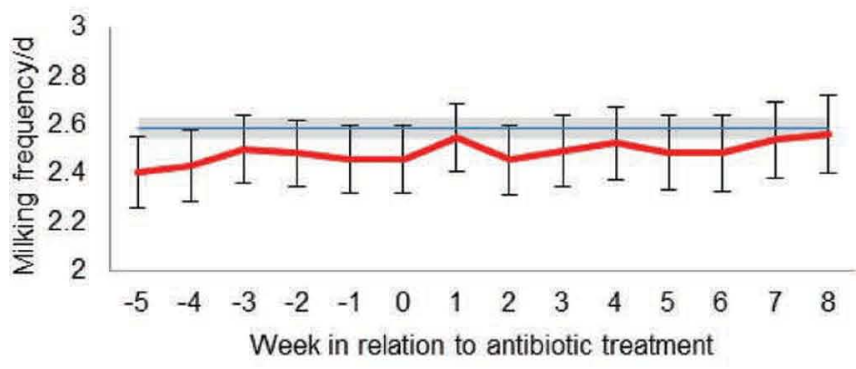

Quarter variation

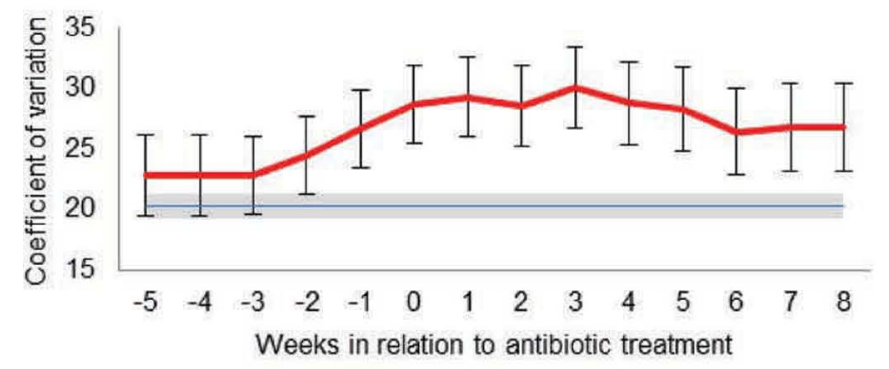

Multiparous cows

Milk yield

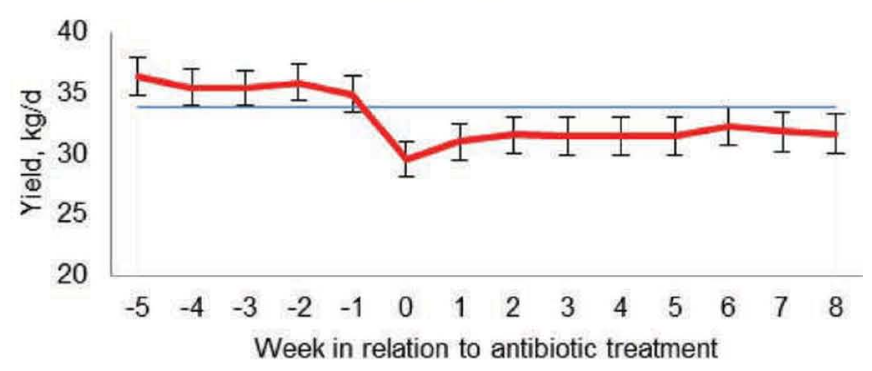

Lactate dehydrogenase

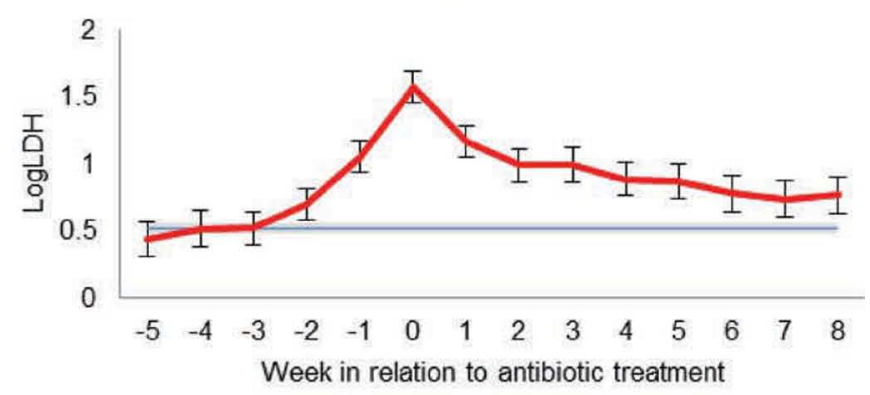

Milking frequency

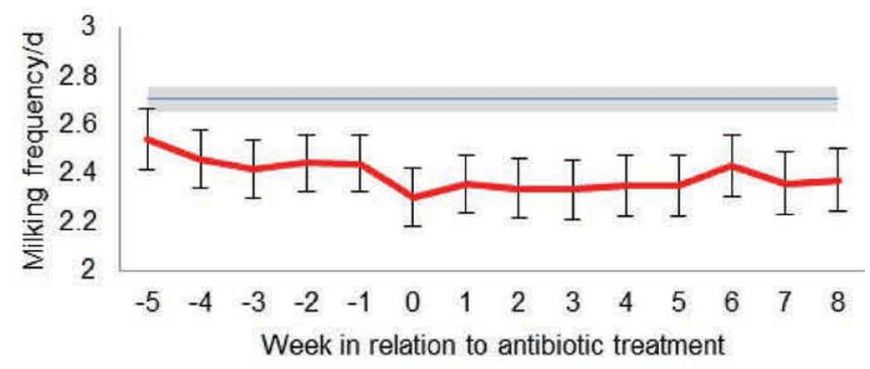

Quarter variation

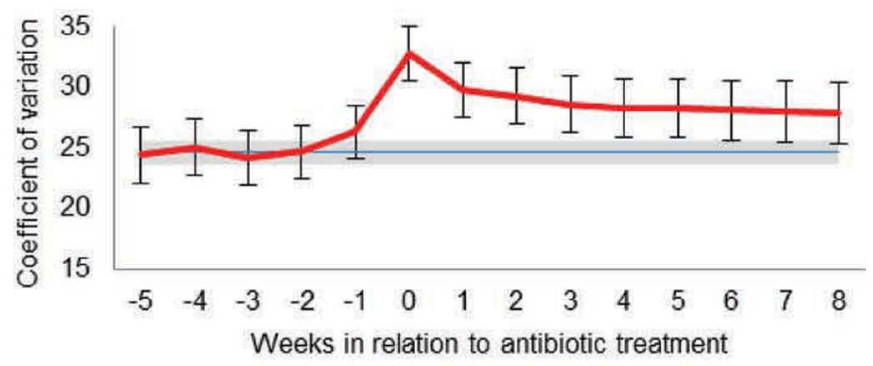

Control Mastitis

Figure 1. The changes in milk yield, lactate dehydrogenase (LDH), milking frequency, and interquarter ratio of yield in relation to antibiotic treatment for mastitis (wk 0) shown as estimated LSM and 95\% confidence limits from a model containing parity, weeks in milk, calving season, mastitis index, and herd. The mastitis group included all the observed mastitis-causing pathogens. Color version available online. 


\section{Staphylococcus aureus}

\section{Primiparous cows}

Milk yield

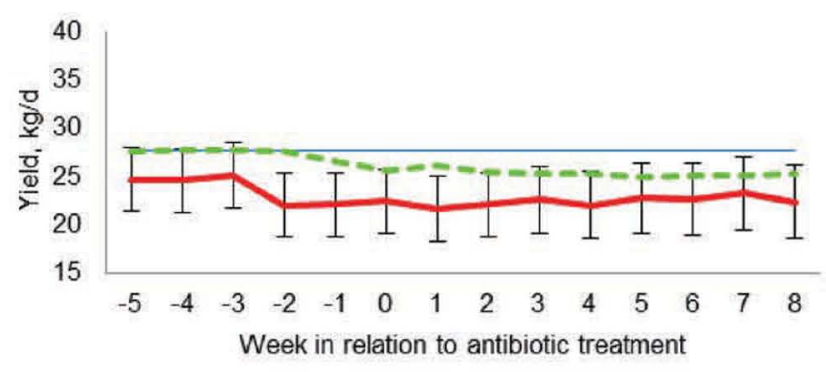

Lactate dehydrogenase

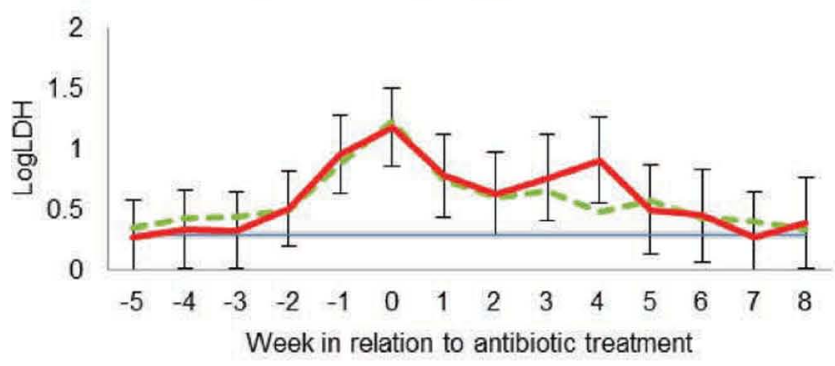

Milking frequency

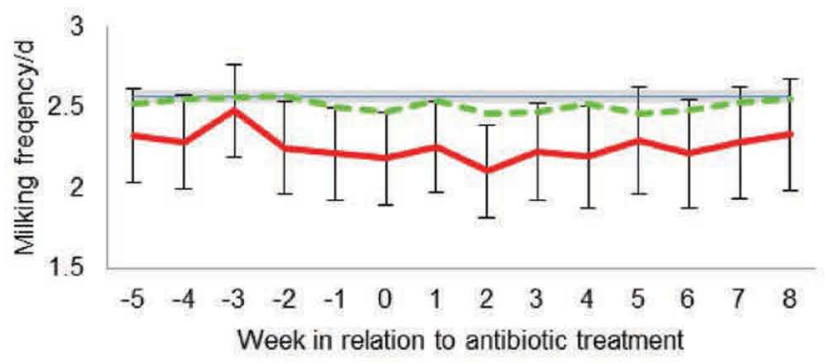

Quarter variation

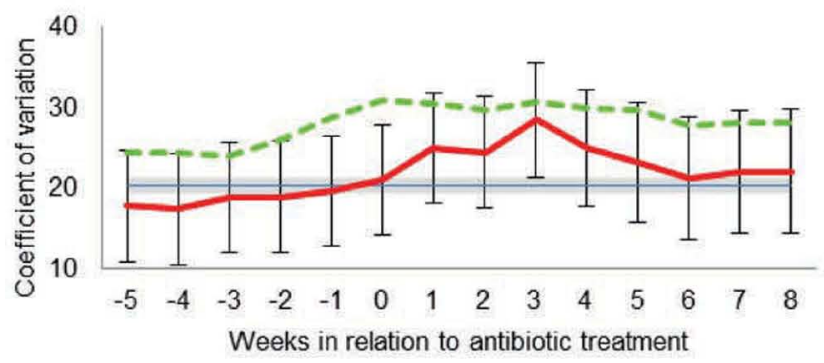

\section{Multiparous cows}

Milk Yield

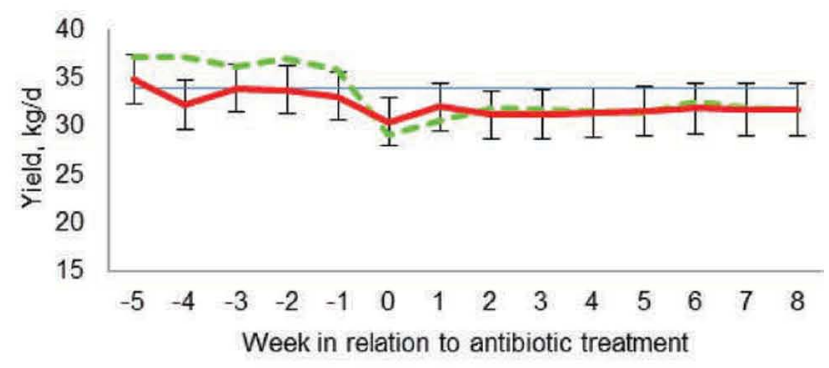

Lactate dehydrogenase

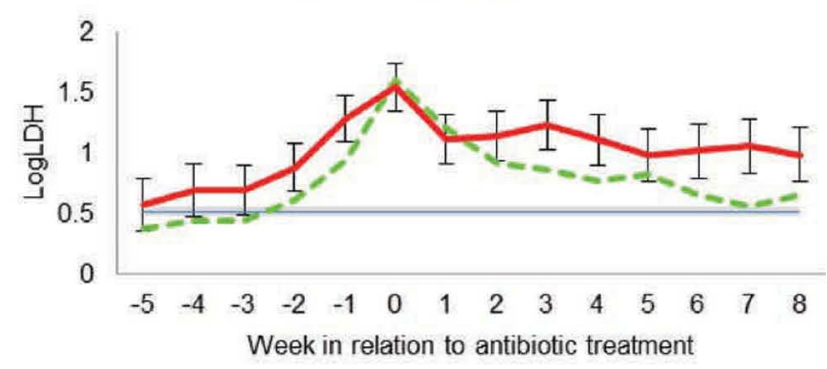

Milking frequency

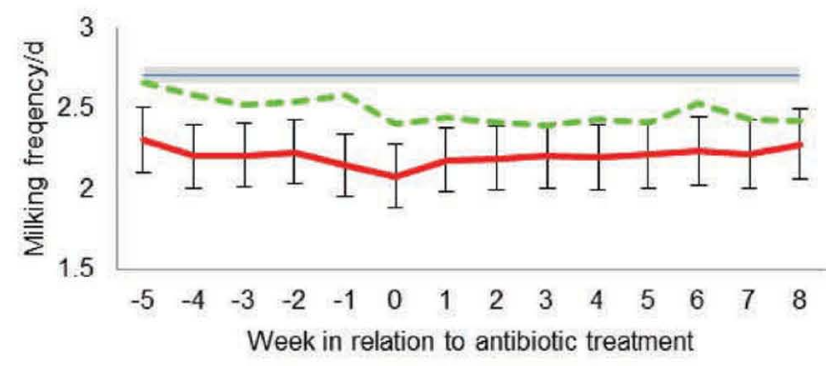

Quarter variation

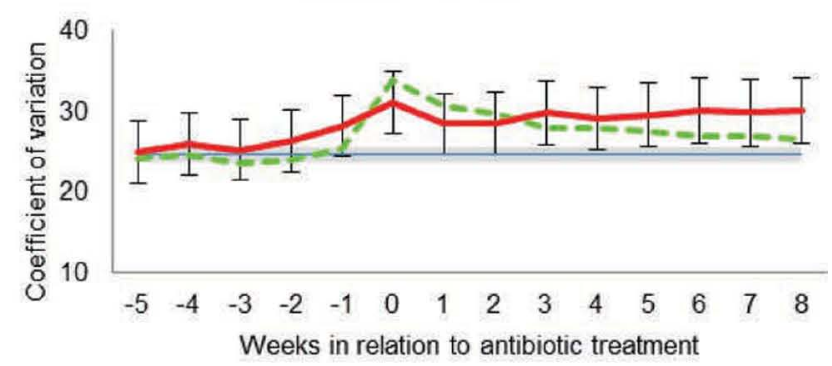

\section{Control $=m$ Other pathogens $\longrightarrow$ Staph. Aureus}

Figure 2. The changes in milk yield, lactate dehydrogenase (LDH), milking frequency, and interquarter ratio of yield in relation to antibiotic treatment for mastitis (wk 0) shown as estimated LSM and 95\% confidence limits from a model containing parity, weeks in milk, calving season, mastitis index, and herd. Other pathogens included all observed mastitis-causing pathogens except for $S$. aureus. Color version available online. 
yield, compared with the controls. Multiparous cows infected with CNS produced more milk than controls and cows with the other types of mastitis when comparing milk production during the entire 14-wk observation period. However, in the weeks after infection, CNS had a detrimental effect on milk production, as the CNSinfected cows produced less milk (Table 2).

Escherichia coli. Escherichia coli mastitis occurred only 5 times in primiparous cows, so no statistical comparison was made on this group. For multiparous cows, 21 cases were diagnosed and treated for $E$. coli mastitis. However, only 9 of these were still in the milking herd one week after treatment. The remaining animals had either been dried off or culled due to the severity of the E. coli infection. Hence, the results from wk 1 to 8 are based on data from only 9 cows. Cows with $E$. coli mastitis were stable for all 4 response variables until wk -1 , after which they deviated markedly from control cows and from cows with mastitis caused by the other pathogens (Figure 4). Escherichia coli mastitis led to some of the highest observed milk losses of around $10 \%$ (Table 2).

\section{DISCUSSION}

This paper is among the first to focus on the recovery period following mastitis cases treated with antibiotics. By use of a retrospective cohort study with time series data from 1,032 lactations and naturally occurring cases of TM, we found reduced milk yield, elevated LDH activity, changes in milking frequency, and elevated IQR of yield. Deviations from baseline levels and from healthy controls could be identified as early as 1 to 3 wk before antibiotic treatment and peaked around the day of treatment. The changes within each variable depended on the involved pathogen, and differences were found between primiparous cows and older animals. In general, cases of TM had detrimental effects on milk production, LDH activity, and IQR of yield, suggesting that the recovery period continued for weeks after antibiotic treatment. These results call for further investigation into management of mastitic dairy cows to optimize recovery, limit milk loss, and ensure animal welfare during the period after treated mastitis.

Our paper presents parallel analyses from several response variables to increase the understanding of the health status of dairy cows after TM. Until now, the majority of reports examining effects of bovine mastitis have focused on milk production as the only outcome variable (Gröhn et al., 2004; Schukken et al., 2009a; Hertl et al., 2014). Even though the present data were collected from only 2 farms, these were specifically selected because of the combination of milking by AMS and access to the Herd Navigator system, thereby giving highly frequent recording of several variables collected on-farm. This approach allows a description of the mastitis period by comparing input from several variables.

Observational studies of naturally occurring diseases will inevitably suffer from potential selection and misclassification biases. In the present study, one of these was the possibility for relapse within the same lactation or in later lactations. As the focus of the present study was on recovery after TM, cows with more than one antibiotic treatment for mastitis within the same lactation were excluded from the data. However, as single lactations within individual cows were considered independent, the possibility of a carry-over effect of TM from earlier lactations cannot be ruled out. Bar et al. (2007) found that cows with one or more clinical mastitis episodes in their previous lactation produced $1.2 \mathrm{~kg}$ of milk per day less in the present lactation compared with cows without clinical mastitis during the previous lactation. Other reports (Schukken et al., 2009a; Hertl et al., 2014) have speculated that previous occurrence of clinical mastitis might reduce the severity of later incidents but have not confirmed this. On the contrary, results of other studies show that the incidence rate of mastitis infection increased after a previous case of clinical mastitis (Houben et al., 1993; Schukken et al., 2009a; Hertl et al., 2014). Due to the chosen inclusion criteria for mastitic and control cows, it cannot be excluded that subclinically infected (Zhao and Lacasse, 2008) or clinically infected cows not receiving antibiotic treatment due to the on-farm treatment protocol might have been included in the control group. This is a second potential source of variation, which challenges the biological basis of the clear definition of control versus infected animals in an observational cohort study such as the present. Clear differences between the control and mastitic cows were still detected, but the influence of the subclinically infected animals on the present results is considered to be minor. However, it is possible that findings of low milk production combined with a slow rise in LDH and IQR of yield before TM may indicate that the involved cows were subclinically infected several weeks before the antibiotic treatment. In addition, in the present data set, the milk production of the primiparous cows treated once for $S$. aureus-induced mastitis during the examined lactation was lower compared with that of the control cows during the entire observation period, leading to a $16 \%$ lower milk production. Hence, in the present study, both changes in relation to control cows as well as changes within mastitic animals were estimated making the used definition of TM cases operational and useful. 


\section{Coagulase-negative staphylococci}

\section{Primiparous cows}

Milk yield

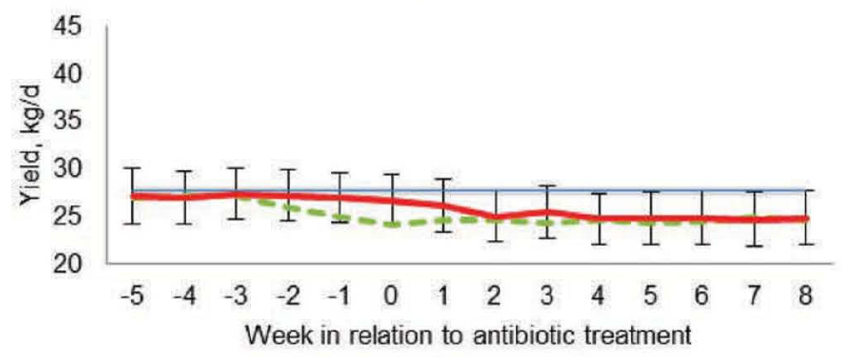

Lactate dehydrogenase

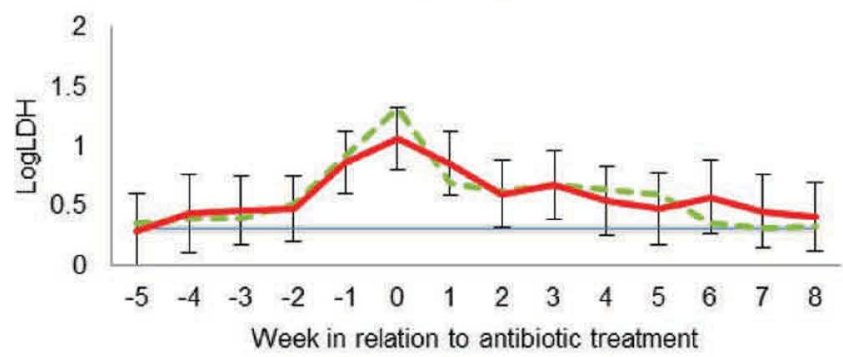

Milking frequency

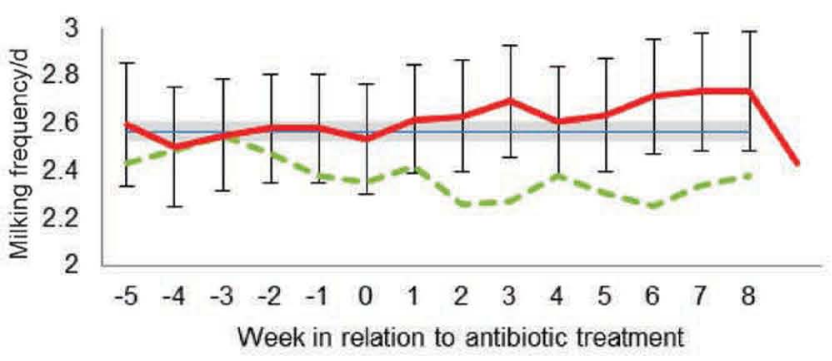

Quarter variation

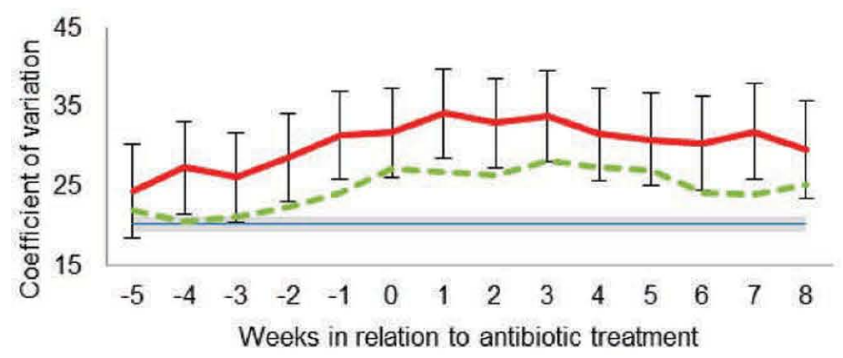

Multiparous cows

Milk yield

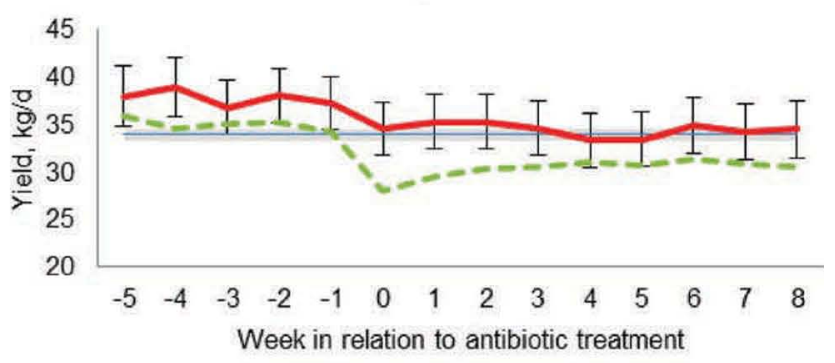

Lactate dehydrogenase

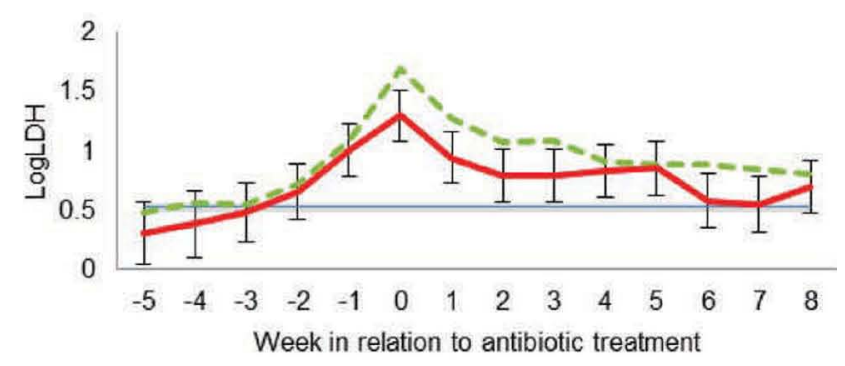

Milking frequency

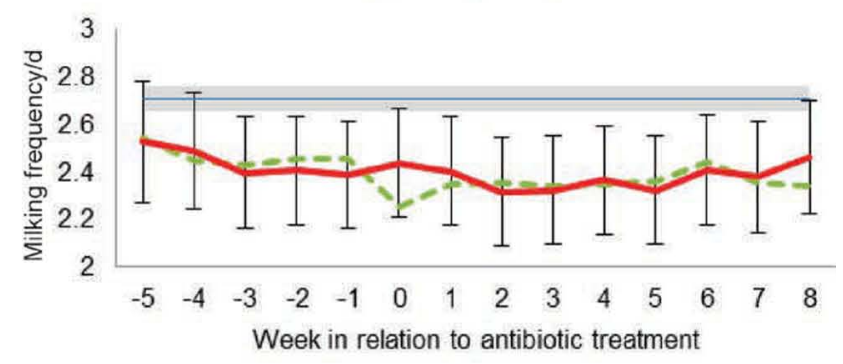

Quarter variation

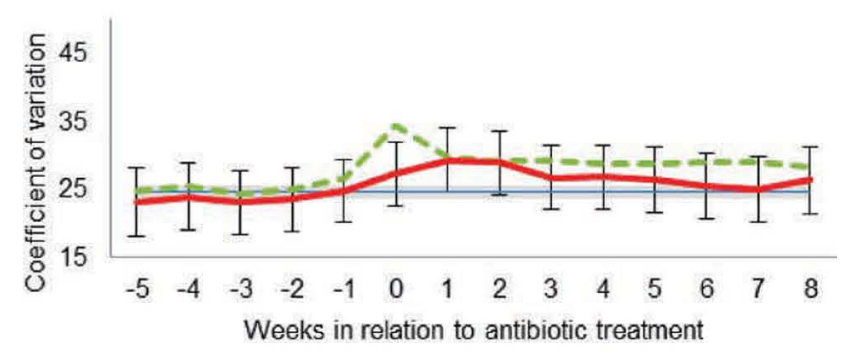

Control $=m$ Other pathogens $=$ CNS

Figure 3. The changes in milk yield, lactate dehydrogenase (LDH), milking frequency, and interquarter ratio of yield in relation to antibiotic treatment for mastitis (wk 0) shown as estimated LSM and 95\% confidence limits from a model containing parity, weeks in milk, calving season, mastitis index, and herd. Other pathogens included all observed mastitis-causing pathogens except for CNS. Color version available online. 


\section{Escherichia coli}

Multiparous cows
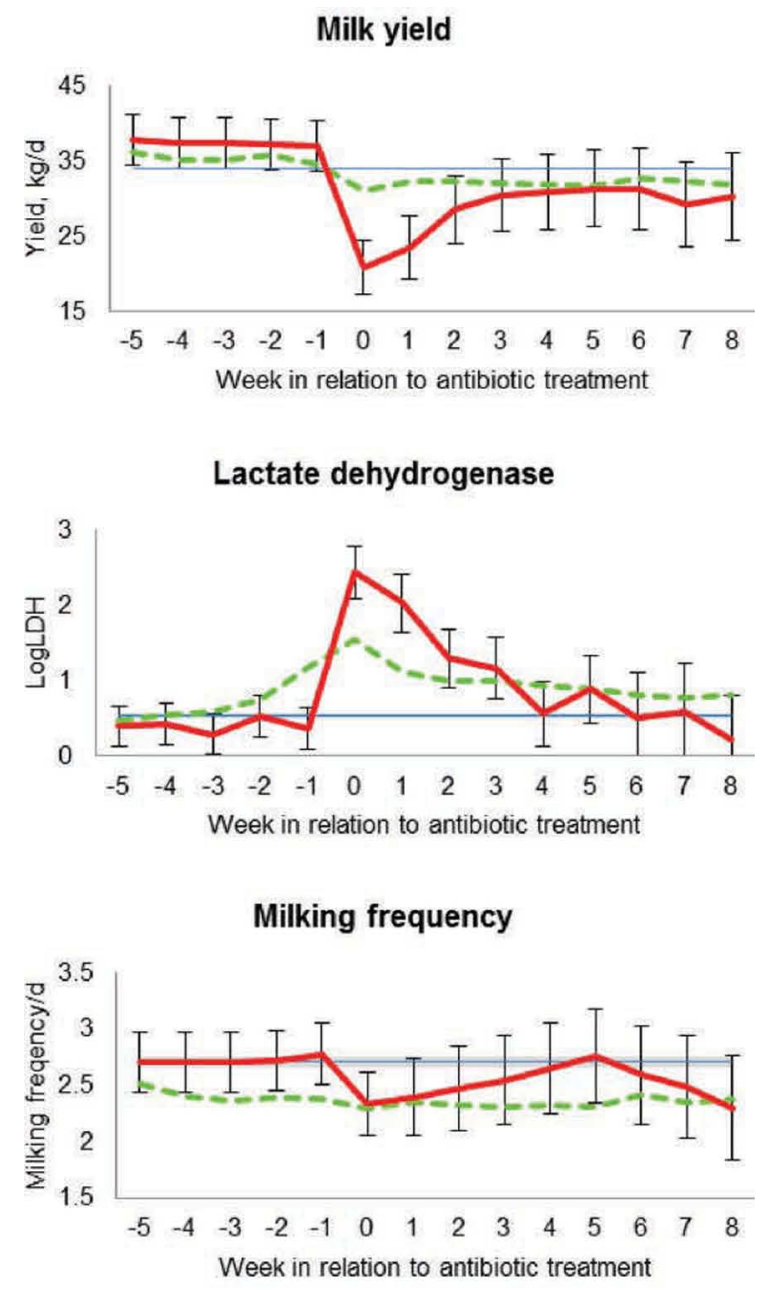

Quarter variation

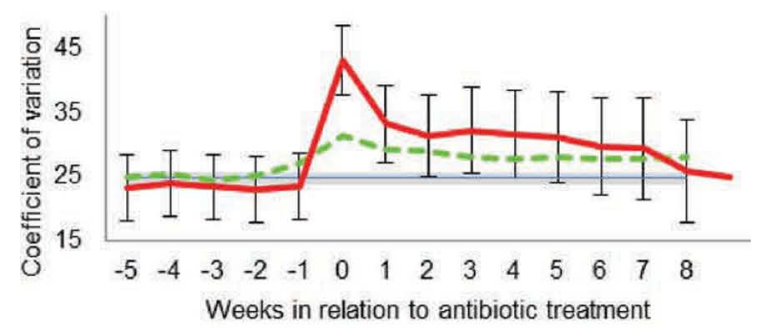

- Control $==-$ Other pathogens $\longrightarrow \mathrm{E}$. coli

Figure 4. The changes in milk yield, lactate dehydrogenase (LDH), milking frequency, and interquarter ratio of yield in relation to antibiotic treatment for mastitis (wk 0) shown as estimated LSM and 95\% confidence limits from a model containing parity, weeks in milk, calving season, mastitis index and herd. Other pathogens included all observed mastitis-causing pathogens except for E. coli. Color version available online.

\section{Effects of TM on Development and Normalization of Measures of Milk Production and Udder Health}

Overall, the present study confirmed earlier findings of a loss in milk production of mastitic cows (Gröhn et al., 2004; Wilson et al., 2004; Schukken et al., 2009a; Hertl et al., 2014) and confirmed the interaction between effects of mastitis and parity on milk production (Gröhn et al., 2004; Hertl et al., 2014). Depending on parity and the involved pathogen, the decreased milk production could be identified as early as 3 to $4 \mathrm{wk}$ before the antibiotic treatment. A clear minimum was not always present, but, if so, it was always found during wk 0 .

Irrespective of the duration of the mastitis-induced effects, the milk loss can be compared with control animals (and then standardized for stage of lactation) or compared with the pre-TM level within single cows. The results showed that when comparing the milk yield of TM cows to their controls, it might seem as though the older cows showed improved recovery compared with the primiparous animals, but this was not the case when comparing yield of single TM cows versus their own premastitis milk production level. Other studies have observed detrimental effects of clinical mastitis on milk production, leading to similar losses (Gröhn et al., 2004; Wilson et al., 2004; Hertl et al., 2014). The present results emphasize the importance of distinguishing between comparisons of milk losses at herd level versus the inclusion of individual losses to fully establish whether cows have recovered from TM.

A stable IQR of yield is evidence that the active quarters of the udder contribute to the total yield with stable proportions. The peak found in IQR of yield corresponded closely to the timing of the decrease in milk yield, hence confirming the lack of stability within quarter yield when cows are suffering from TM. In general, the IQR of yield leveled out after TM, but remained at a higher level than before the disease. This finding suggests that the milk production stabilized, but that one or more quarters suffered a persistent loss in milk production as a consequence of TM, and that this change lasted for longer than the experimental period of $8 \mathrm{wk}$ postmastitis. The IQR of yield has not previously been used to evaluate the recovery period after mastitis. However, the calculation of IQR of yield contributes to the knowledge about normalization of the udder after mastitis and may be included in future studies combined with milk production data.

In the present data set, a general increase in the $\mathrm{LDH}$ activity was found from 1 to 2 wk before the antibiotic treatment, the peak of which was found in the week of diagnosis and antibiotic treatment. Such an increase deviates from the normal postcalving increase (Nyman 
et al., 2014) and is explained as a breakdown of cell tissue during the infection of the udder (Bogin et al., 1976). As discussed for the milk yield, the mastitisinduced increase in LDH activity depended on the parity of the cows as well as the involved pathogen. Within the primiparous cows, the $\mathrm{LDH}$ response was rather similar across the studied groups of pathogens and returned to baseline levels, as well as the level of the control animals, within the present study period. The LDH response of the multiparous cows was more varied, and when using the overall model the elevated LDH activity did not normalize to control or baseline levels but reached a stable plateau 3 to 4 wk after the antibiotic treatment. These results indicate that, despite the treatment with antibiotics, the udders might still have been affected by TM, as the elevated LDH activity indicated persisting injuries in one or more quarters (Bogin et al., 1976). However, as ours is the first study of LDH activity during the recovery period after TM, the findings of an elevated but stable LDH activity for weeks after a mastitis infection warrants further investigation.

Data on milking frequency were included in the present study, as cows milked by AMS have some possibility to change the milking frequency, which would be expected to decrease during times of disease, as a result of discomfort and malaise (Fitzpatrick et al., 1998; Leslie et al., 2010). In general, in AMS herds, milking frequency is expected to correlate with individual milk yield due to the settings in the AMS, as described earlier (Løvendahl and Chagunda, 2011). However, the present findings regarding milking frequency exemplify the complexity of relations between disease outbreak and productivity within the dairy industry, as the multiparous cows had a higher premastitis milk yield than the control animals, but a significantly lower milking frequency. In addition, the expected drop in milking frequency during TM was not observed. Thus, this variable, which is often reported from systems based on AMS milking, can probably not be used directly as an indicator of udder health status. However, one may speculate whether some cows may have had a nonoptimal milking strategy within farm, thereby predisposing certain animals to become infected with mastitis. This possibility warrants further studies of the connection between milking frequency, milk yield, and the incidence of mastitis infections.

\section{Effects of Involved Pathogens on the Development and Normalization in Measures of Milk Production and Udder Health}

The distribution of the involved pathogens matches earlier reports (Gröhn et al., 2004; Hertl et al., 2014;
Nyman et al., 2014), with S. aureus, E. coli, and CNS being among the most abundant and a general finding of a higher infection rate in multiparous than in primiparous cows. Thirty percent of the TM cases were caused by $S$. aureus, and within this group of animals the effects of TM depended strongly on cow parity. Given the pathogenesis of $S$. aureus mammary infections, which often result in subclinical mastitis and relatively low cure rates (Zhao and Lacasse, 2008), the observed premastitis decrease in milk production and elevated LDH activity were expected for the multiparous animals. The elevated LDH levels pre- and postmastitis correspond to earlier findings of elevated SCC in the same period for $S$. aureus mastitis (de Haas et al., 2004) and were confirmed by the remaining high IQR of yield, suggesting that the production of one or more quarters did not recover within the study period. The finding of normalization of LDH as well as IQR of yield in the primiparous cows infected with $S$. aureus, despite a remaining decrease in milk production of $5 \%$, emphasizes the complexity of the recovery process.

Mammary infections cultured positive for CNS were responsible for $28 \%$ of the cases within the present study, and this pathogen was the primary cause of mastitis within the primiparous animals. The changes in milk yield, LDH, milking frequency, and IQR of yield in the cases cultured positive for CNS were similar to those of the category containing all the other pathogens. For the multiparous cows, a high premastitis milk yield was found, combined with a relatively small decrease in milk production at the time of antibiotic treatment. Compared with the control animals and the other types of TM, cows infected with CNS produced more milk during the entire observation period. Similar findings have been reported by Piepers et al. (2013), who observed that heifers infected with CNS in early lactation were slightly higher producers later in lactation than culture-negative heifers. Similarly, Schukken et al. (2009b) and Gröhn et al. (2004) reported elevated yield in multiparous cows with CNS both pre- and postinfection. Consequently, in the present study, when pre- versus postmastitis milk yield were compared, multiparous cows infected with CNS had the smallest observed loss of only $2 \%$, which is only $18 \%$ of the loss induced by E. coli.

Hence, even though effects of CNS - such as the other examined pathogens - interacted with parity, which complicates the interpretation, the present results suggest (based on milk yield, LDH activity, and IQR of yield) that CNS led to less severe cases of mastitis and confirm earlier results (Vanderhaeghen et al., 2014). However, despite the milder cases of mastitis, CNS still has detrimental effects on milk production resulting in economic losses for the farmer (Gröhn et al., 2004). 
Effects of this particular category of pathogens on dairy cow behavior and welfare have so far not been examined, and the severity of these infections cannot fully be determined. In addition, recent findings (Fry et al., 2014; reviewed by Vanderhaeghen et al., 2014) raise questions about the homogeneity of CNS as a pathogen category, as some bacteria species seem to be more virulent than others. Thus, further research is needed to make conclusions about the severity of CNS mastitis and its recovery.

The third examined category of cultured pathogens from infected udders, E. coli, resulted in fast, drastic, and short-lasting responses for all 4 variables. Importantly, only a few cases could be included in the data modeling the recovery period (9 animals), and none of these were primiparous. Before the infection, these cows were high yielding but otherwise comparable to the controls for the quantified parameters. Cows with low SCC have been shown to be more vulnerable to gram-negative pathogens, such as E. coli (Schukken et al., 1989; Wellnitz et al., 2010). The same may have happened in the present study with low LDH activity [which is closely correlated with SCC (Nyman et al., 2014)] in the weeks before the antibiotic treatment. Cases of E. coli mastitis are known to be severe and may result in death or culling of the infected individuals. Similarly, in the present data set, more than half of the E. coli-infected cows were culled or dried off in the first week after the antibiotic treatment. Hence, the severe effect on milk production may have been expected given the pathogenesis of this infection. Gröhn et al. (2004) found similar losses in milk yield of around $10 \%$ in multiparous cows infected with E. coli. The described dichotomy of the recovery of $E$. coli-infected individuals, where some had to be euthanized or dried off and some recovered relatively quickly, makes it difficult to put forward a general conclusion regarding normalization after this type of mammary infection and makes comparison with other pathogen categories difficult. However, our results emphasize the difficulties regarding studies of effects of bovine mastitis where the involved pathogens are not controlled for or stratified.

Irrespective of the pathogens involved and the parity of the cows, the present results show prolonged effects of TM on milk production as well as IQR of yield and LDH activity. When normalization was found, within the present observation period, it was protracted and often stabilized at different levels than before the infections. These findings indicate that the health status of the udder was changed. Some consequences of this are clear, such as the loss of milk production, translating into an economic loss for the farmers. However, the consequences for the cow in terms of animal welfare are not readily apparent from the changes in LDH activity, milk production, or IQR of yield. To understand the reported effects of TM in terms of cow welfare, further research is needed linking these variables to measures of welfare, such as cow behavior or clinical condition of the udders (Welfare Quality, 2009). Bovine clinical mastitis has been shown to lead to behavioral changes such as reduced lying behavior and clinical signs of infection in the udders (Medrano-Galarza et al., 2012), and recent results suggest that behavioral effects of bovine clinical mastitis may also persist after antibiotic treatment (Fogsgaard et al., 2015). However, at present, examinations of the possible relations between changes in udder health status, as reported here, and the behavior or welfare of the animals have not, to our knowledge, been conducted.

\section{CONCLUSIONS}

Mastitis treated with antibiotics resulted in reduced milk yield, elevated LDH activity, changes in milking frequency, and elevated IQR of yield. Deviations from baseline levels and from healthy controls could be identified as early as 1 to $3 \mathrm{wk}$ before antibiotic treatment and peaked around treatment days. The changes in each variable depended on the involved pathogen, and differences were found between primiparous cows and older animals. To correctly estimate the effects of TM and the recovery status of the cow, it is important to take the individual cow into account and not limit comparison to herd level, as the latter may mask the true magnitude of the changes. However, in general, cases of TM were shown to have detrimental effects on milk production, LDH activity, and IQR of yield suggesting that the recovery period continued for weeks after the antibiotic treatment. These results call for further investigation into management of mastitic dairy cows to optimize recovery, limit milk loss, and ensure animal welfare during the period after mastitis.

\section{ACKNOWLEDGMENTS}

The authors gratefully acknowledge Martin Bjerring (Department of Animal Science, Aarhus University) for his extensive work with data capture from databases and data handling. Great thanks to Mette S. Herskin (Department of Animal Science, Aarhus University) for her input during the entire project and with her help formulating and shaping this manuscript. The authors thank owners and personnel from Dairies A and B. The project was funded by the BIOSENS project, granted by the Danish Ministry of Food, Agriculture and Fisheries Copenhagen, Denmark (Innovations Law), Lattec A/S (Hillerod, Denmark), and the Danish Cattle Association (Aarhus, Denmark). 


\section{REFERENCES}

Bar, D., Y. T. Gröhn, G. Bennett, R. N. Gonzàlez, J. A. Hertl, H. F. Schulte, L. W. Tauer, F. L. Welcome, and Y. H. Schukken. 2007. Effect of repeated episodes of generic clinical mastitis on milk yield in dairy cows. J. Dairy Sci. 90:4643-4653.

Bogin, E., G. Ziv, and J. Avidar. 1976. Enzyme-activities in normal and inflamed bovine udder tissues. Zentralblatt für Veterinärmedizin Reihe A 23:460-466. http://dx.doi.org/10.1111/j.1439-0442.1976. tb01726.x.

Chagunda, M. G., T. Larsen, M. Bjerring, and K. L. Ingvartsen. 2006b. L-Lactate dehydrogenase and N-acetyl- $b$-D-glucosaminidase activities in bovine milk as indicators of non-specific mastitis. J. Dairy Res. 73:431-440.

Chagunda, M. G. G., N. C. Friggens, M. D. Rasmussen, and T. Larsen. 2006a. A model for detection of individual cow mastitis based on an indicator measured in milk. J. Dairy Sci. 89:2980-2998.

de Haas, Y., R. F. Veerkamp, H. W. Barkema, Y. T. Gröhn, and Y. H. Schukken. 2004. Associations between pathogen-specific cases of clinical mastitis and somatic cell count patterns. J. Dairy Sci. $87: 95-105$.

Ersbøll, A. K., N. Toft, and J. Bruun. 2004. Observational studies, Pages 47-60 in Introduction to Veterinary Epidemiology. H. Houe, A. K. Ersbøll, and N. Toft, ed. Biofolia, Frederiksberg C, Denmark.

Fitzpatrick, J. L., F. J. Young, D. Eckersall, D. N. Louge, C. J. Knight, and A. Nolan. 1998. Recognising and controlling pain and inflammation in mastitis. Pages 36-44 in Vol. Proceedings of the British Mastitis Conference. Institute for Animal Health, West Midlands (UK), Stoneleigh, Coventry, UK.

Fogsgaard, K. K., T. W. Bennedsgaard, and M. S. Herskin. 2015. Behavioral changes in freestall-housed dairy cows with naturally occurring clinical mastitis. J. Dairy Sci. 98:1730-1738.

Fry, P. R., J. R. Middleton, S. Dufour, J. Perry, D. Scholl, and I. Dohoo. 2014. Association of coagulase-negative staphylococcal species, mammary quarter milk somatic cell count, and persistence of intramammary infection in dairy cattle. J. Dairy Sci. 97:4876-4885.

Gröhn, Y. T., D. J. Wilson, R. N. Gonzàlez, J. A. Hertl, H. Schulte, G. Bennett, and Y. H. Schukken. 2004. Effect of pathogen-specific clinical mastitis on milk yield in dairy cows. J. Dairy Sci. $87: 3358-3374$

Hertl, J. A., Y. H. Schukken, F. L. Welcome, L. W. Tauer, and Y. T. Groehn. 2014. Pathogen-specific effects on milk yield in repeated clinical mastitis episodes in Holstein dairy cows. J. Dairy Sci. 97:1465-1480.

Houben, E. H. P., A. A. Dijkhuizen, J. A. M. Van Arendonk, and R. B. M. Huirne. 1993. Short- and long-term production losses and repeatability of clinical mastitis in dairy cattle. J. Dairy Sci. $76: 2561-2578$

ICAR. 2011. ICAR Rules, standards and guidelines for dairy production recording. Section 2 (2.1.8). In International Agreement of Recording Practices. Accessed August 2015. http://www. icar.org/documents/Rules\%20and\%20regulations/Guidelines/ Guidelines_2014.pdf .

Leslie, K., C. Kielland, and S. Millman. 2010. Is mastitis painful and is therapy for pain beneficial? Pages 114-130 in NMC Annual Meeting Proceedings. Natl. Mastitis Counc., Madison, WI.
Løvendahl, P., and M. G. G. Chagunda. 2011. Covariance among milking frequency, milk yield, and milk composition from automatically milked cows. J. Dairy Sci. 94:5381-5392.

Medrano-Galarza, C., J. Gibbons, S. Wagner, A. M. de Passille, and J. Rushen. 2012. Behavioral changes in dairy cows with mastitis. J. Dairy Sci. 95:6994-7002.

National Mastitis Council. 1999. Laboratory Handbook on Bovine Mastitis. Revised edition. National Mastitis Council Inc., Madison, WI.

Norberg, E., H. Hogeveen, I. R. Korsgaard, N. C. Friggens, K. H. M. N. Sloth, and P. Løvendahl. 2004. Electrical conductivity of milk: Ability to predict mastitis status. J. Dairy Sci. 87:1099-1107.

Nyman, A. K., K. Persson Waller, T. W. Bennedsgaard, T. Larsen, and U. Emanuelson. 2014. Associations of udder-health indicators with cow factors and with intramammary infection in dairy cows. J. Dairy Sci. 97:5459-5473.

Piepers, S., Y. H. Schukken, P. Passchyn, and S. De Vliegher. 2013 The effect of intramammary infection with coagulase-negative staphylococci in early lactating heifers on milk yield throughout first lactation revisited. J. Dairy Sci. 96:5095-5105.

Rutten, C. J., A. G. J. Velthuis, W. Steeneveld, and H. Hogeveen. 2013. Invited review: Sensors to support health management on dairy farms. J. Dairy Sci. 96:1928-1952.

Schukken, Y. H., D. van de Geer, F. J. Grommers, J. A. Smit, and A Brand. 1989. Intramammary infections and risk factors for clinical mastitis in herds with low somatic cell counts in bulk milk. Vet. Rec. 125:393-396.

Schukken, Y. H., R. N. Gonzàlez, L. L. Tikofsky, H. F. Schulte, C. G. Santisteban, F. L. Welcome, G. J. Bennett, M. J. Zurakowski, and R. N. Zadoks. 2009b. CNS mastitis: Nothing to worry about? Vet. Microbiol. 134:9-14.

Schukken, Y. H., J. Hertl, D. Bar, G. J. Bennett, R. N. Gonzàlez, B. J. Rauch, C. Santisteban, H. F. Schulte, L. Tauer, F. L. Welcome, and Y. T. Gröhn. 2009a. Effects of repeated gram-positive and gram-negative clinical mastitis episodes on milk yield loss in Holstein dairy cows. J. Dairy Sci. 92:3091-3105.

Vanderhaeghen, W., S. Piepers, F. Leroy, E. Van Coillie, and F. Haesebrouck. 2014. Invited review: Effect, persistence, and virulence of coagulase-negative Staphylococcus species associated with ruminant udder health. J. Dairy Sci. 97:5275-5293.

Welfare Quality. 2009. Welfare Quality Assessment Protocol for Cattle. Welfare Quality Consortium, Lelystad, Netherlands.

Wellnitz, O., A. Baumert, M. Saudenowa, and R. M. Bruckmaier. 2010. Immune response of bovine milk somatic cells to endotoxin in healthy quarters with normal and very low cell counts. J. Dairy Res. 77:452-459.

Wilson, D. J., R. N. Gonzàlez, J. Hertl, H. F. Schulte, G. J. Bennett, Y. H. Schukken, and Y. T. Gröhn. 2004. Effect of clinical mastitis on the lactation curve: A mixed model estimation using daily milk weights. J. Dairy Sci. 87:2073-2084.

Wood, P. D. P. 1969. Factors affecting the shape of the lactation curve in cattle. Anim. Sci. 11:307-316.

Zhao, X., and P. Lacasse. 2008. Mammary tissue damage during bovine mastitis: Causes and control. J. Anim. Sci. 86(suppl):57-65. 